\title{
The volatiles of pathogenic and nonpathogenic mycobacteria and related bacteria
}

\author{
Thorben Nawrath ${ }^{1}$, Georgies F. Mgode ${ }^{2,3}$, Bart Weetjens ${ }^{4}$, \\ Stefan H. E. Kaufmann ${ }^{2}$ and Stefan Schulz ${ }^{* 1}$
}

\section{Full Research Paper}

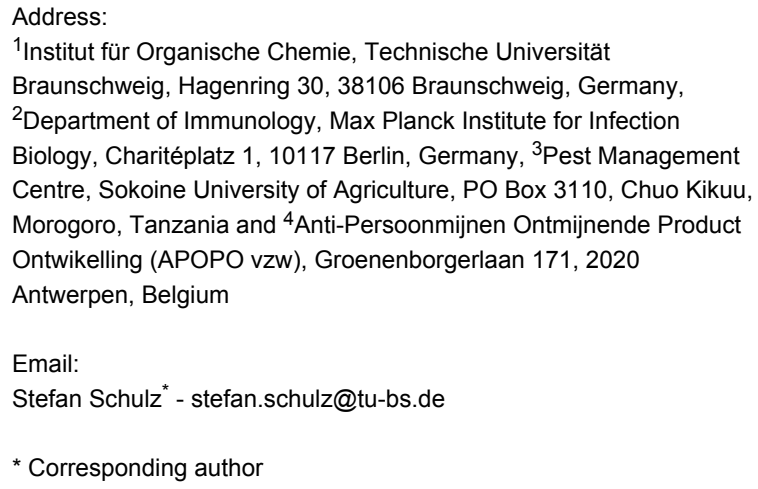

Beilstein J. Org. Chem. 2012, 8, 290-299. doi:10.3762/bjoc.8.31

Received: 08 December 2011

Accepted: 30 January 2012

Published: 22 February 2012

This article is part of the Thematic Series "Biosynthesis and function of secondary metabolites".

Guest Editor: J. S. Dickschat

(C) 2012 Nawrath et al; licensee Beilstein-Institut. License and terms: see end of document.

\begin{abstract}
Volatiles released by pathogenic and nonpathogenic mycobacteria, as well as by mycobacteria-related Nocardia spp., were analyzed. Bacteria were cultivated on solid and in liquid media, and headspace samples were collected at various times during the bacterial lifecycle to elucidate the conditions giving optimal volatile emission. Emitted volatiles were collected by using closedloop stripping analysis (CLSA) and were analyzed by gas-chromatography-mass-spectrometry. A wide range of compounds was produced, although the absolute amount was small. Nevertheless, characteristic bouquets of compounds could be identified. Predominantly aromatic compounds and fatty-acid derivatives were released by pathogenic/nonpathogenic mycobacteria, while the two Nocardia spp. (N. asteroides and N. africana) emitted the sesquiterpene aciphyllene. Pathogenic Mycobacterium tuberculosis strains grown on agar plates produced a distinct bouquet with different volatiles, while liquid cultures produce less compounds but sometimes an earlier onset of volatile production because of their steeper growth curves under this conditions. This behavior differentiates M. tuberculosis from other mycobacteria, which generally produced fewer compounds in seemingly lower amounts. Knowledge of the production of volatiles by M. tuberculosis can facilitate the rational design of alternative and faster diagnostic measures for tuberculosis.
\end{abstract}

\section{Introduction}

Tuberculosis (TB) remains one of the most threatening diseases on earth. In 2008, up to 2 million people died as a result of TB infection [1]. The causative agent, M. tuberculosis, has a highly flexible physiology and metabolism that allows it to adapt to changes in the environment during the course of an infection [2]. Other pathogenic mycobacteria cause diseases such as 
leprosy, evoked by $M$. leprae, or buruli ulcer, due to infection by $M$. ulcerans $[3,4]$. In addition, numerous nonpathogenic and facultative pathogenic mycobacteria exist.

Although several diagnostic measures have been developed for TB diagnosis [5,6], most of these techniques are expensive, e.g., immunological tests using antigens, DNA analysis, or specific culturing conditions, especially for developing countries with the highest burden of TB [7-9]. Thus, the analyses of speciesspecific volatiles obtained from breath samples of potentially infected individuals, or from the bacteria themselves, have recently been proposed for rapid diagnosis of TB [8-11]. The feasibility of these methods is supported by reports that trained Cricetomys rats can distinguish between sputum samples from TB-infected and noninfected persons $[12,13]$.

While the first studies based on electronic sensors or fuzzylogic experiments gave promising results $[8,10]$, recent studies have focused on the characteristic compounds released by pathogenic M. bovis and M. tuberculosis strains [9,11]. Compounds from these species were also expected to occur in breath samples from TB patients $[8,10]$. In these studies, volatiles were collected by using solid-phase micro-extraction (SPME). Methyl phenylacetate (1), methyl $p$-anisate (2), methyl nicotinate (3), and $o$-phenylanisole (4) were emitted by pathogenic $M$. bovis and M. tuberculosis (Figure 1), while nontuberculous mycobacteria did not produce these four compounds [9]. Due to a central role in mycobacterial metabolism [14], nicotinic acid, closely related to $(\mathbf{3})$, was used in these studies as a reference compound from the breath of TB-positive patients [11] Infected individuals also released nicotinic acid (excluding smoking patients in this study), proving the utility of this approach [11].

Nevertheless, a broad analysis of the volatiles produced by $M$. tuberculosis, nontuberculous mycobacteria and mycobacteriarelated species has not been performed. This knowledge is of utmost importance in the identification of potential compounds for use in pattern-recognition methods, such as electronic noses and trained Cricetomys rats. We report here on the identification of volatiles produced by different strains of $M$. tuberculosis, as well as of M. smegmatis, M. aurum, M. neoaurum,
M. aichiense, $M$. scrofulaceum, M. avium spp. avium, $M$. vaccae, Nocardia africana, and N. asteroides, using closed-loop stripping analysis (CLSA) for the collection of volatile compounds $[15,16]$. This method allows sampling for longer periods than SPME, and usually results in a lower detection limit. Compounds not detectable by SPME can thus be detected. SPME preferentially favors less volatile compounds [17]. Furthermore, SPME may have a discriminative effect, and our experience has shown that minor components are often not detected when large amounts of a major component are present.

The investigated mycobacteria were in different stages of their lifecycles and grown on various different media. The volatiles released under these conditions were identified and their formation under different conditions is discussed.

\section{Results and Discussion}

Volatiles released from different mycobacteria and Nocardia spp. grown on solid or in liquid media were collected by using CLSA as described previously $[15,16]$. The headspace extracts were analyzed by gas-chromatography-mass-spectrometry (GC-MS). Compound identification was performed by comparison of mass spectra and gas-chromatographic retention indices with those of authentic reference compounds and massspectra libraries [18].

\section{Analysis of bacteria grown on a solid medium}

Different strains of $M$. tuberculosis grown on a $7 \mathrm{H} 11$ solid medium were analyzed after different incubation periods (days). The detection of bacteria-specific compounds was assured by the analysis of headspace samples from a sterile medium incubated in parallel with bacterial strains. Although many compounds were released from the medium, bacteria-specific compounds were distinguishable. A typical gas chromatogram is shown in Figure 2, revealing that many compounds are formed from the nutrient medium that is necessary to grow the bacteria. The identified compounds are listed in Table 1.

In addition to previously reported compounds 1-4 [9], several new volatiles were identified, predominantly aromatic compounds, such as 4-methylanisole (5), methyl salicylate (6), methyl 2-aminobenzoate (7), and methyl and ethyl benzoate (8

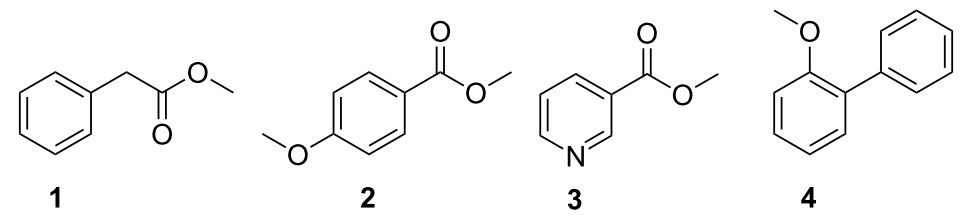

Figure 1: Volatile compounds released by Mycobacterium tuberculosis and M. bovis identified in previous studies [9]. 


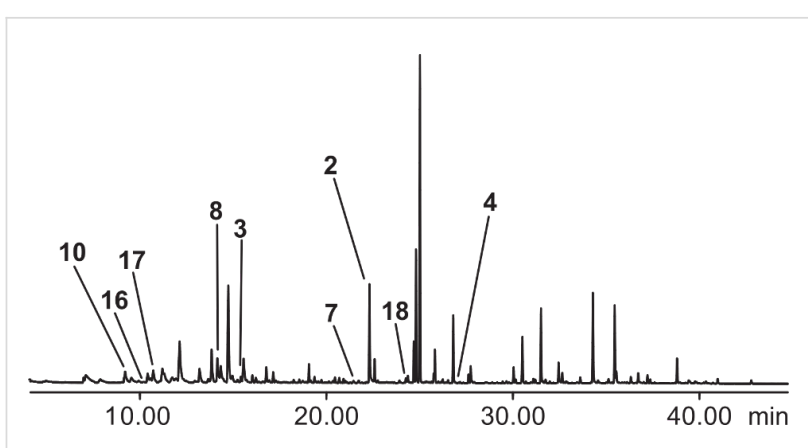

Figure 2: Total ion chromatogram of a headspace extract of a culture of Mycobacterium tuberculosis strain 2, grown on a $7 \mathrm{H} 11$ solid medium. Nonlabeled peaks originate from the nutrient medium.

and 9), as well as fatty-acid derivatives, for example, 4-pentanolide (10) (Figure 3). Many of the compounds listed in Table 1 are known volatiles from other bacteria [19].

As shown in Table 1, early cultures produced few compounds; only those older than 18 days produced a bouquet of compounds. This is probably due to the slow growth of many mycobacteria $[7,20]$. Increased production of volatile compounds occurred in the stationary phase (i.e., starting after three weeks of growth), a phenomenon that corroborates the recent findings that $M$. tuberculosis culture is detected by trained rats mostly at this growth stage [20]. A full description of the growth stages used in this report has recently been published [20]. The analyses of cultures of $M$. smegmatis, M. aurum, $M$. neoaurum, M. aichiense, M. scrofulaceum, M. avium ssp. avium, and M. vaccae revealed that these diverse nontuberculous mycobacteria did not produce as many different compounds as $M$. tuberculosis (Table 2), and what they did produced was often in lower quantities. The exceptions are M. scrofulaceum and M. avium ssp. avium, which cause cervical lymphadenitis in children and avian TB, as well as opportunistic infections in immunocompromised humans $[21,22]$.

Although certain volatile, aromatic compounds, such as $\mathbf{1}, \mathbf{6 , 8}$, and $\mathbf{9}$, were produced in some cases, many compounds from extracts of M. tuberculosis were absent in the other mycobacteria. The low emission rate of volatile compounds was not a result of the early stage at which the mycobacteria were analyzed, since all strains were fast-growing [20,21,23-28]. Interestingly, some of the bacteria emitted sulfur-containing compounds, such as dimethyl disulfide (11), dimethyl trisulfide

Table 1: Volatiles released by Mycobacterium tuberculosis grown on a $7 \mathrm{H} 11$ solid medium. ${ }^{\text {a }}$

\begin{tabular}{|c|c|c|c|c|c|c|}
\hline Compound & I & strain 1 & strain 2 & strain 5 & strain 6 & H37Ra \\
\hline 4-Hydroxy-4-methylpentan-2-one (14) & 847 & $---b$ & $---+c$ & $-+-----d$ & $---e$ & $-{ }^{f}$ \\
\hline 4-Pentanolide (10) & 950 & +++ & +++ & --++++ & +++ & + \\
\hline Methyl 2-furoate (15) & 978 & --- & ++-+ & --++--- & ++- & + \\
\hline 3-Methyl-4-pentanolide (16) ${ }^{\mathrm{g}}$ & 984 & -++ & ++++ & ------- & --- & - \\
\hline Unknown & 1006 & --+ & +-+- & --+++++ & --+ & - \\
\hline Unknown & 1021 & ++- & ++-+ & ------- & --- & - \\
\hline 4-Methylanisol (5) & 1021 & --+ & --+- & --+++++ & --+ & - \\
\hline Unknown & 1084 & -++ & +++- & --+++++ & -++ & - \\
\hline Methyl benzoate (8) & 1093 & +++ & ++++ & +++++++ & +++ & + \\
\hline 2-Phenylethanol ${ }^{\mathrm{h}}$ & 1113 & +++ & ++++ & -++++++ & +++ & - \\
\hline 4-Methyl-5-hexanolide $(17)^{\mathrm{g}}$ & 1133 & --- & -++- & ------- & --- & - \\
\hline Methyl nicotinate ${ }^{\mathrm{C}}(\mathbf{3})$ & 1136 & +++ & ++++ & -+++++ & +++ & - \\
\hline Ethyl benzoate $(\mathbf{9})$ & 1169 & --- & ---- & ---++++ & --- & + \\
\hline Methyl phenylacetate (1) & 1177 & ++- & -+++ & ---++++ & +++ & - \\
\hline Methyl salicylate $(\mathbf{6})$ & 1193 & +-- & ---- & --+---+ & -+- & + \\
\hline Benzothiazole & 1222 & --- & ---+ & ---+--- & --- & - \\
\hline Methyl 2-aminobenzoate (7) & 1341 & --- & ++-- & ---+--- & --- & - \\
\hline Methyl $p$-anisate $(\mathbf{2})$ & 1376 & +++ & ++++ & -++++++ & +++ & - \\
\hline Ethyl $p$-anisate (18) & 1450 & -+- & ++-- & -+++-++ & ++- & - \\
\hline 2-Phenylanisol (4) & 1559 & +++ & ++++ & -++++++ & +++ & - \\
\hline
\end{tabular}

al: gas-chromatographic retention index on DB-5; +: compound detected in sample; -: compound not detected in sample. ${ }^{\mathrm{b}}$ The results of three analyses are shown for each experiment performed on differently aged cultures: 25 days (d), $26 \mathrm{~d}, 32 \mathrm{~d}$. ${ }^{\mathrm{C}}$ The results of four analyses are shown for each experiment performed on differently aged cultures: $20 \mathrm{~d}, 22 \mathrm{~d}, 30 \mathrm{~d}, 33 \mathrm{~d}$. ${ }^{\mathrm{d}}$ The results of seven analyses are shown for each experiment

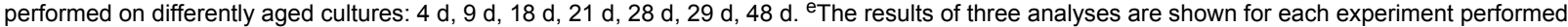

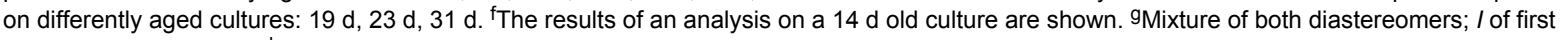
eluting isomer is shown. ${ }^{\mathrm{h}}$ Traces present in the medium. 
<smiles>COc1ccc(C)cc1</smiles>

5<smiles>COC(=O)c1ccccc1O</smiles>

6<smiles>COC(=O)c1ccccc1N</smiles>

7<smiles>[R]OC(=O)c1ccccc1</smiles>

$8 \mathrm{R}=\mathrm{Me}$ $9 \mathrm{R}=\mathrm{Et}$<smiles>CC1CCC(=O)O1</smiles>

10<smiles>CSSSSSSSC</smiles><smiles>CC(=O)CC(C)(C)O</smiles><smiles>COC(=O)c1ccco1</smiles>

11

12

13

14

15<smiles>CC1CC(=O)OC1C</smiles>

16<smiles>CC1CCC(=O)OC1C</smiles>

17<smiles>CCOC(=O)c1ccc(OC)cc1</smiles>

18

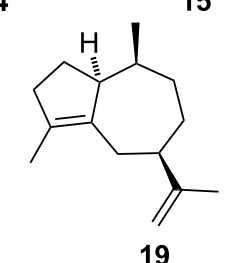

Figure 3: Volatiles released by mycobacteria and Nocardia spp. grown on a $7 \mathrm{H} 11$ solid medium.

Table 2: Volatiles released by diverse nontuberculous mycobacteria grown on a $7 \mathrm{H} 11$ solid medium. ${ }^{a}$

\begin{tabular}{|c|c|c|c|c|c|c|c|c|}
\hline Compound & l & Msm & Mau & $\mathrm{Mn}$ & Mai & Msc & Maa & $\mathrm{Mv}$ \\
\hline Dimethyl disulfide (11) & & $---^{b}$ & $++-c$ & $+++d$ & $---^{e}$ & $--^{f}$ & $--g$ & $--^{h}$ \\
\hline 4-Pentanolide (10) & 950 & +++ & +++ & +++ & +++ & ++ & ++ & -- \\
\hline Dimethyl trisulfide (12) & 969 & -+- & ++- & +++ & --- & -- & -- & -- \\
\hline Methyl 2-furoate (15) & 978 & --- & --- & --- & --- & ++ & -- & -- \\
\hline 3-Methyl-4-pentanolide $(\mathbf{1 6})^{\mathrm{i}}$ & 984 & --- & --- & --- & --- & -- & -+ & -- \\
\hline 6-Methylhept-5-en-2-one & 988 & --- & --- & --- & --- & -- & ++ & -- \\
\hline Unknown & 1006 & --- & --- & --- & --- & ++ & -+ & -- \\
\hline Methyl benzoate (8) & 1093 & --- & --- & --- & --- & ++ & -- & -- \\
\hline 2-Phenylethanolj & 1111 & ++- & --- & -- & --- & ++ & ++ & -- \\
\hline Ethyl benzoate (9) & 1169 & --- & --- & --- & --- & ++ & -- & -- \\
\hline Methyl phenylacetate (1) & 1177 & --- & --- & --- & --- & ++ & +- & -- \\
\hline Methyl salicylate (6) & 1193 & --- & --- & --- & --- & ++ & -+ & -- \\
\hline Dimethyl tetrasulfide (13) & 1206 & --- & --- & +++ & --- & -- & -- & -- \\
\hline Ethyl salicylate & 1270 & --- & --- & --- & --- & ++ & -- & -- \\
\hline Methyl methylsalicylate & 1315 & --- & --- & --- & -- & -- & ++ & ++ \\
\hline Unknown sesquiterpenes & & --- & --+ & --- & +++ & -- & -- & ++ \\
\hline
\end{tabular}

a: gas-chromatographic retention index on DB-5; +: compound detected in sample; -: compound not detected in sample. Msm: M. smegmatis, Mau: M. aurum, Mn: M. neoaurum, Mai: $M$. aichiense, Msc: M. scrofulaceum, Maa: $M$. avium ssp. avium, Mv: $M$. vaccae. ${ }^{b}$ The results of three analyses are shown for each experiment performed on differently aged cultures: $2 \mathrm{~d}, 3 \mathrm{~d}, 4 \mathrm{~d}$. ${ }^{\mathrm{C}}$ The results of three analyses are shown for each experiment performed on differently aged cultures: $4 \mathrm{~d}, 5 \mathrm{~d}, 11 \mathrm{~d}$. ${ }^{\mathrm{d}}$ The results of three analyses are shown for each experiment performed on differently aged cultures: $5 \mathrm{~d}, 6 \mathrm{~d}, 13 \mathrm{~d}$. ${ }^{\text {T}}$ The results of three analyses are shown for each experiment performed on differently aged cultures: $3 \mathrm{~d}, 8 \mathrm{~d}, 9 \mathrm{~d}$. ${ }^{\mathrm{f}}$ The results of two analysis are shown for each experiment performed on differently aged cultures: $6 \mathrm{~d}, 11 \mathrm{~d}$. 9The results of two analysis are shown for each experiment performed on differently aged cultures: $5 \mathrm{~d}, 11 \mathrm{~d}$. ${ }^{\text {h}}$ The results of two analysis are shown for each experiment performed on differently aged cultures: $4 \mathrm{~d}, 7 \mathrm{~d}$. ' / of first eluting isomer is shown. 'ंTraces present in the medium.

(12), and dimethyl tetrasulfide (13), which are known bacterial volatiles [19]; these compounds were not emitted from M. tuberculosis.

While the mycobacteria grown on the $7 \mathrm{H} 11$ solid medium emitted a wide variety of volatiles, Nocardia asteroides produced, even in different ages, only 4-pentanolide (10) (Table 3). Additionally, N. africana also released only one compound, the sesquiterpene aciphyllene (19), which is a known volatile from several plants [29], and the endophytic fungus Muscodor albus [30]. The structure of $\mathbf{1 9}$ has recently been revised [29]. This compound may act as marker for norcardiae, 


\begin{tabular}{|c|c|c|c|c|c|c|c|}
\hline \multirow[t]{2}{*}{ Compound } & \multirow[t]{2}{*}{ I } & \multicolumn{3}{|c|}{ N. asteroides } & \multicolumn{3}{|c|}{ N. africana } \\
\hline & & $5 d$ & $16 \mathrm{~d}$ & $18 \mathrm{~d}$ & $3 d$ & $6 \mathrm{~d}$ & $10 \mathrm{~d}$ \\
\hline 4-Pentanolide (10) & 950 & + & + & + & - & - & - \\
\hline Aciphyllene (19) & 1499 & - & - & - & + & + & + \\
\hline
\end{tabular}

al: gas-chromatographic retention index on DB-5; +: compound detected in sample; -: compound not detected in sample; d: days.

as it was produced as a single compound by Nocardia spp. grown on a $7 \mathrm{H} 11$ medium and has so far not been reported for other bacteria [19].

\section{Analysis of bacteria grown in diverse liquid media}

In these experiments, two different media were used for culturing bacteria. Nocardia spp. were only cultured on the 7H9 broth medium, and all mycobacteria were grown on the $7 \mathrm{H} 9$ broth and the Sauton liquid media. The results of the analyses of different strains of $M$. tuberculosis grown on the $7 \mathrm{H} 9$ broth medium are shown in Figure 4 and Table 4.

A 33-day-old culture of M. tuberculosis strain 2, and a 6-dayold culture of strain 5 produced the largest variety of compounds. Again, aromatic compounds including the previously observed volatiles $\mathbf{1}, \mathbf{5}, \mathbf{7}$, and $\mathbf{8}$, as well as the fatty acid derivative 10, were present in the headspace extracts.<smiles>CCCCCCO</smiles>

20<smiles>Oc1ccccc1</smiles>

21<smiles>CC12CCC(CC1=O)C2(C)C</smiles>

22<smiles>CC(=O)OCc1ccccc1</smiles>

23<smiles>[R]C1CC2C=CC=C1C(=O)OCC2</smiles>

$24 \mathrm{R}=\mathrm{Me}$

Figure 4: Volatiles released by $M$. tuberculosis grown in a $7 \mathrm{H} 9$ broth liquid medium.

\begin{tabular}{|c|c|c|c|c|c|c|c|c|c|}
\hline \multirow[t]{2}{*}{ Compound } & \multirow[t]{2}{*}{ l } & \multicolumn{2}{|c|}{ Strain 2} & \multicolumn{4}{|c|}{ Strain 5} & \multicolumn{2}{|c|}{ Strain 6} \\
\hline & & $12 \mathrm{~d}$ & $33 d$ & $3 d$ & $6 \mathrm{~d}$ & $10 \mathrm{~d}$ & $13 d$ & $14 d$ & $15 d$ \\
\hline 1-Hexanol (20) & 890 & - & - & + & - & - & - & - & - \\
\hline 4-Pentanolide (10) & 950 & + & + & - & + & + & - & + & - \\
\hline Methyl butenolide & 979 & - & + & - & + & - & - & - & - \\
\hline Phenol (21) & 984 & - & + & - & & - & - & - & - \\
\hline Unknown & 1021 & - & + & + & + & - & - & - & - \\
\hline 4-Methylanisol (5) & 1021 & - & + & - & + & - & - & - & - \\
\hline Methyl benzoate (8) & 1093 & - & + & - & + & - & + & + & + \\
\hline 2-Phenylethanol ${ }^{b}$ & 1113 & + & - & - & + & + & + & + & + \\
\hline Methyl nicotinate $(3)^{\mathrm{b}}$ & 1136 & - & - & - & + & - & - & - & + \\
\hline Camphor (22) & 1143 & - & - & + & + & - & - & - & + \\
\hline Benzyl acetate (23) & 1164 & - & + & - & & - & - & - & - \\
\hline Methyl phenylacetate (1) & 1177 & - & - & - & + & - & - & + & + \\
\hline Benzothiazole & 1222 & - & + & - & - & - & - & - & - \\
\hline Methyl 2-aminobenzoate (7) & 1341 & - & + & - & - & - & - & - & - \\
\hline Methyl dimethylbenzoate (24) & 1348 & - & + & - & - & - & - & + & - \\
\hline
\end{tabular}

a: gas-chromatographic retention index on DB-5; +: compound detected in sample; -: compound not detected in sample; d: days. ${ }^{\text {b }}$ Traces present in the medium. 
Frequently, mycobacteria are observed to grow faster in liquid medium than on solid medium [31,32]. Consistent with this, $M$. tuberculosis strain 5 produced the most volatiles after six days of growth, unlike cultures of the same age grown on solid medium. Heavy inoculation of a fresh medium with a liquid culture of M. tuberculosis at the exponential growth phase may also generate a high yield of volatiles. Several volatiles released in the solid-medium experiments were not observed in liquid culture, and vice versa. On a solid medium, compounds 14-18 were formed but were not emitted in liquid cultures. In contrast, liquid cultures of $M$. tuberculosis released 1-hexanol (20), phenol (21), camphor (22), benzyl acetate (23), methyl dimethylbenzoate (24), and a methyl butenolide, all of which were absent in strains cultured on a solid medium.

The headspace extracts of the nontuberculous mycobacteria cultured in the $7 \mathrm{H} 9$ broth medium were investigated and the results (Table 5) revealed that most of the nontuberculous mycobacteria produced only a few volatiles, with the exception of M. scrofulaceum and M. avium ssp. avium, which produced a larger variety of compounds, including various aromatic volatiles also emitted by $M$. tuberculosis.

The analyses of the Nocardia strains revealed interesting differences between the two media types. Although aciphyllene (19) was again produced by N. africana, it was also present in the bouquet of an early culture of $N$. asteroides (Table 6). Additionally, both bacteria produced several unknown diterpenoids. Such relatively large compounds have rarely been reported as bacterial volatiles [33,34].

In additional experiments, a Sauton liquid medium was used to culture M. tuberculosis (Table 7). The two strains of $M$. tuberculosis produced fewer volatiles compared to cultures on

\begin{tabular}{|c|c|c|c|c|c|c|c|c|c|c|}
\hline \multirow[t]{2}{*}{ Compound } & \multirow[t]{2}{*}{ I } & \multirow{2}{*}{$\begin{array}{l}\text { Msm } \\
8 \mathrm{~d}\end{array}$} & \multirow{2}{*}{$\begin{array}{l}\text { Mau } \\
6 \mathrm{~d}\end{array}$} & \multicolumn{2}{|l|}{$\mathrm{Mn}$} & \multicolumn{2}{|c|}{ Mai } & \multirow{2}{*}{$\begin{array}{l}\text { Msc } \\
9 \mathrm{~d}\end{array}$} & \multirow{2}{*}{$\begin{array}{l}\text { Maa } \\
10 d\end{array}$} & \multirow{2}{*}{$\begin{array}{l}\mathrm{Mv} \\
8 \mathrm{~d}\end{array}$} \\
\hline & & & & $7 \mathrm{~d}$ & $13 d$ & $5 d$ & $14 \mathrm{~d}$ & & & \\
\hline 2-Methylbutanol & & - & - & - & - & - & - & + & - & - \\
\hline Methyl isovalerate & & - & - & - & - & - & - & + & - & - \\
\hline 1-Hexanol (20) & 890 & + & - & - & - & - & - & - & - & - \\
\hline Isobutyl isobutyrate & 919 & - & - & - & - & - & - & + & - & - \\
\hline 4-Pentanolide (10) & 950 & + & - & - & - & - & - & - & + & + \\
\hline Methyl butenolide & 979 & & + & + & + & + & + & - & - & - \\
\hline 3-Methyl-4-pentanolide $(16)^{b}$ & 984 & - & - & - & - & - & - & - & - & + \\
\hline Methyl benzoate (8) & 1093 & - & - & - & - & - & - & + & + & - \\
\hline 2-Phenylethanolc & 1111 & + & - & - & - & - & - & + & + & + \\
\hline Camphor (22) & 1143 & - & - & - & - & - & - & - & - & + \\
\hline Methyl phenylacetate (1) & 1177 & - & - & - & - & - & - & + & + & - \\
\hline Methyl salicylate (6) & 1193 & - & - & - & - & - & - & + & + & + \\
\hline Indole & 1289 & - & - & - & - & + & + & - & - & - \\
\hline 2-Aminoacetophenone & 1299 & + & - & - & - & - & - & - & - & - \\
\hline Methyl dimethylbenzoate (24) & 1348 & - & - & - & - & - & - & + & + & - \\
\hline
\end{tabular}

al: gas-chromatographic retention index on DB-5; +: compound detected in sample; -: compound not detected in sample; d: days; Msm: $M$. smegmatis, Mau: M. aurum, Mn: M. neoaurum, Mai: M. aichiense, Msc: M. scrofulaceum, Maa: M. avium ssp. avium, Mv: M. vaccae. b Mixture of both diastereomers. ${ }^{\mathrm{C}}$ Traces present in the medium.

Table 6: Volatiles released by Nocardia asteroides and $N$. africana grown in the $7 \mathrm{H} 9$ broth medium. ${ }^{\text {a }}$

\begin{tabular}{|c|c|c|c|c|c|c|}
\hline \multirow[t]{2}{*}{ Compound } & \multirow[t]{2}{*}{ I } & \multicolumn{2}{|c|}{ N. asteroides } & \multicolumn{3}{|c|}{ N. africana } \\
\hline & & $4 d$ & $14 d$ & $2 \mathrm{~d}$ & $5 d$ & $11 \mathrm{~d}$ \\
\hline Aciphyllene (19) & 1499 & + & - & + & + & + \\
\hline Unknown diterpenoids & & + & - & + & - & + \\
\hline
\end{tabular}

al: gas-chromatographic retention index on DB-5; +: compound detected in sample; -: compound not detected in sample; d: days. 
Table 7: Volatiles released by Mycobacterium tuberculosis grown in a Sauton liquid medium. ${ }^{\text {a }}$

\begin{tabular}{|c|c|c|c|c|c|}
\hline \multirow[t]{2}{*}{ Compound } & \multirow[t]{2}{*}{ I } & \multicolumn{3}{|c|}{ Strain 5} & \multirow{2}{*}{$\begin{array}{l}\text { Strain } 6 \\
25 d\end{array}$} \\
\hline & & $24 \mathrm{~d}$ & $26 \mathrm{~d}$ & $46 \mathrm{~d}$ & \\
\hline 2-Hydroxypentan-3-one & & - & - & - & + \\
\hline Trimethyloxazole & & - & + & + & + \\
\hline Unknown & 947 & - & - & + & + \\
\hline Benzylalcohol & 1035 & - & + & - & + \\
\hline Phenylacetaldehyde & 1041 & - & - & - & + \\
\hline Methyl benzoate (8) & 1093 & - & - & + & - \\
\hline 2-Phenylethanol ${ }^{\mathrm{b}}$ & 1113 & + & + & + & + \\
\hline Methyl phenylacetate (1) & 1177 & - & - & + & - \\
\hline Methyl $p$-anisate (2) & 1376 & - & - & + & - \\
\hline Methyl dimethylbenzoate (24) & 1348 & - & - & + & - \\
\hline
\end{tabular}

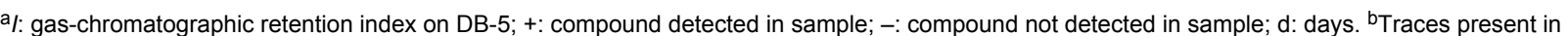
the medium.

the solid medium of the same age. The growth of M. tuberculosis in the Sauton liquid medium was slower than in other liquid media. Thus, the type of medium used influenced the production of volatiles. Few volatiles were produced, including predominantly aromatic compounds, such as $\mathbf{1 , 2 , 8}$, and $\mathbf{2 4}$, especially in the 46-day-old culture of M. tuberculosis strain 5 .

Analyses of the headspace extracts from nontuberculous mycobacteria grown in the Sauton medium (M. smegmatis, M. aurum, M. neoaurum, M. aichiense, and M. avium ssp. avium) showed that fewer compounds were produced by these species in this medium (Table 8).

As observed for the 7H9 medium, only M. avium ssp. avium emitted a diverse array of volatiles, while the other mycobac- teria produced a few compounds only. The results of different analyses showed that M. tuberculosis produces more compounds than the previously described volatiles 1-4, especially on the solid medium.

Apart from the production of specific compounds such as $\mathbf{3}$ and 4, M. tuberculosis was characterized by a more pronounced production of volatiles compared to other mycobacteria and associated Nocardia bacteria. While many of these compounds, such as 2-phenylethanol, $\mathbf{1}$, or $\mathbf{8}$, are commonly found in some, but not all, bacteria [19], the individual components contribute to a specific bouquet of volatiles. This bouquet probably enables olfactory detection of M. tuberculosis by trained Cricetomys rats [13], or could enable potential detection by electronic noses. Only M. scrofulaceum and M. avium ssp. avium

\begin{tabular}{|c|c|c|c|c|c|c|}
\hline Compound & & Msm & Mau & $\mathrm{Mn}$ & Mai & Maa \\
\hline 2-Hydroxypentan-3-one & & $---b$ & $----c$ & $----d$ & $--e^{e}$ & $+f$ \\
\hline Benzylalcohol & 1035 & ++- & ---- & ++-- & --+ & + \\
\hline Methyl benzoate (8) & 1093 & --- & ---- & ---- & --- & + \\
\hline Linalool & 1099 & --- & ---- & +--- & +-- & + \\
\hline 2-Phenylethanolg & 1113 & +++ & ---- & ++-- & --- & + \\
\hline Methyl phenylacetate (1) & 1177 & --- & ---- & ---- & --- & + \\
\hline Methyl dimethylbenzoate (24) & 1348 & --- & ---- & ---- & --- & + \\
\hline Unknown sesquiterpenes & & ++- & ---- & ---- & --- & + \\
\hline
\end{tabular}

al: gas-chromatographic retention index on DB-5; +: compound detected in sample; -: compound not detected in sample. Msm: $M$. smegmatis, Mau: M. aurum, Mn: M. neoaurum, Mai: M. aichiense, Maa: $M$. avium ssp. avium. ${ }^{\text {b }}$ The results of three analyses are shown for each experiment performed

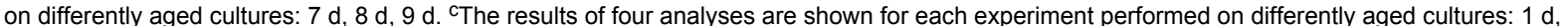
$7 \mathrm{~d}, 11 \mathrm{~d}, 12 \mathrm{~d}$. ${ }^{\mathrm{d}}$ The results of four analyses are shown for each experiment performed on differently aged cultures: $5 \mathrm{~d}, 6 \mathrm{~d}, 10 \mathrm{~d}, 20 \mathrm{~d}$. ${ }^{\text {e}}$ The results of three analyses are shown for each experiment performed on differently aged cultures: $8 \mathrm{~d}, 9 \mathrm{~d}, 10 \mathrm{~d}$. ${ }^{\mathrm{f}}$ The results of an analysis on day 10 is shown. 9Traces present in the medium. 
were found to produce a nutrient mixture of volatiles while other strains did not. The volatiles identified belonged predominantly to the biosynthetic class of aromatic compounds, while metabolites of the fatty-acid-biosynthesis pathway were also present.

Since M. tuberculosis grown in the Sauton liquid medium produced only a few volatiles after more than 25 days, these experimental conditions are suboptimal. M. tuberculosis cultivated in the 7H9 broth medium emitted after a shorter incubation time more volatiles in comparison to cultures grown in solid medium. However, the number of volatiles produced compared to nontuberculous mycobacteria was much lower than for mycobacteria grown on solid medium. The compounds emitted by M. tuberculosis grown on the $7 \mathrm{H} 9$ broth medium are known, except for 3, but are also released from other bacteria, thus diminishing their diagnostic potential $[19,35,36]$. Compound 19 may play a role as a marker for different Nocardia strains, depending on growth conditions. Further studies should focus on enhancing the production of volatiles in liquid medium, which support the rapid growth of bacteria. Currently the identified volatile compounds produced by M. tuberculosis are tested for tuberculosis detection by using Cricetomys rats.

\section{Conclusion}

In conclusion, profound qualitative and quantitative differences (number of compounds as well as probably higher emission rates) in the bouquet of volatiles from M. tuberculosis, nontuberculous mycobacteria and other bacteria grown on different media were found. M. tuberculosis produces a distinctive bouquet of compounds, consisting of compounds known to be produced by other bacteria, but also including relatively specific compounds such as methyl nicotinate (3). Variations occurred within individual analyses and also between different media. Therefore, it seems unlikely that GC-MS analyses of individual cultures can be used as a diagnostic tool. Nevertheless, a system able to detect mixtures within a given compositional tolerance seems more promising. In this sense, trained Cricetomys rats seem to be well suited for detection [20]. In a more technical variant, experiments with electronic noses, able to discriminate between different odor profiles, seem to be more promising for the detection of $M t b$-specific odor profiles and, thus, could be potentially used for TB diagnosis.

\section{Experimental}

\section{Media and growth conditions}

Bacterial colonies from a 7H11 solid medium (Becton, Dickinson \& Co., Sparks, USA, see Supporting Information File 1) or bacteria culture $(100 \mu \mathrm{L})$ from a $7 \mathrm{H} 9$ liquid medium (Becton, Dickinson \& Co., Sparks, USA, see Supporting Information File 1) were inoculated on a 7H11 solid medium and were spread out with sterile disposable loops to cover the entire plate/ medium surface. Plates were wrapped in parafilm and aerobically incubated at $28-37{ }^{\circ} \mathrm{C}$.

For bacteria grown in the $7 \mathrm{H} 9$ liquid medium, the inoculum $(500 \mu \mathrm{L})$ was aseptically transferred from actively growing cultures and inoculated into fresh medium $(15-20 \mathrm{~mL})$. Cultures were incubated at $28-37^{\circ} \mathrm{C}$ under aerobic conditions.

Bacterial cultures for inoculation into Sauton medium (without glycerol) were washed in order to remove traces of ingredients from the stock-culture medium (7H9). Washing was done three times by mixing the culture $(3 \mathrm{~mL})$ with phosphate-buffered saline (PBS; $10 \mathrm{~mL}$ ) and centrifuging at $4000 \mathrm{rpm}$ for $10 \mathrm{~min}$. Supernatants were decanted and PBS $(10 \mathrm{~mL})$ was added to the pellet, which was dissolved by careful pipetting. The suspension was centrifuged again at $4000 \mathrm{rpm}$ for $10 \mathrm{~min}$. The final pellet was suspended in sterile PBS (4 mL), mixed thoroughly and $500 \mu \mathrm{L}$ of the suspension was subcultured into fresh Sauton medium $(30 \mathrm{~mL})$. The Sauton medium consisted of the following ingredients in $1000 \mathrm{~mL}$ of distilled water: asparagine (4 g), $\mathrm{MgSO}_{4}(0.5 \mathrm{~g}), \mathrm{K}_{2} \mathrm{PO}_{4}(0.5 \mathrm{~g})$, citric acid (1.83 g), ferric ammonium citrate $(0.05 \mathrm{~g})$, D- $(+)$-glucose monohydrate $(4.82 \mathrm{~g})$, and sodium pyruvate $(4.82 \mathrm{~g})$. The $\mathrm{pH}$ was adjusted to 6.8 and the medium was filter-sterilized by using a $0.22 \mu \mathrm{m}$ membrane filter (Millipore Corp., USA). Cultures were incubated at $37^{\circ} \mathrm{C}$ aerobically.

\section{Sampling of volatiles}

Volatile organic compounds emitted by cell cultures of the different mycobacteria were collected by using the CLSA technique $[14,15]$. The volatiles were adsorbed on charcoal (Chromtech; Precision Charcoal Filter, $5 \mathrm{mg}$ ) for $24 \mathrm{~h}$, and then eluted with $30 \mu \mathrm{L}$ of $\mathrm{CH}_{2} \mathrm{Cl}_{2}$. The obtained extracts were immediately analyzed by GC-MS, and stored at $-30^{\circ} \mathrm{C}$.

\section{GC-EIMS analysis}

GC-EIMS analyses of the samples were carried out on a HP-6890 GC system connected to a HP-5973 mass-selective detector fitted with a BPX5 fused-silica capillary column (25 m, $0.22 \mathrm{~mm}$ i.d., $0.25 \mu \mathrm{m}$ film; SGE, Australia), or on an Agilent 7890A connected with an Agilent 5975C inert mass detector fitted with a HP-5MS fused silica capillary column $(30 \mathrm{~m}$, $0.25 \mathrm{~mm}$ i.d., $0.25 \mu \mathrm{m}$ film; J\&W Scientific, USA). Conditions for the HP-6890/HP-5973 system were as follows: Inlet pres-

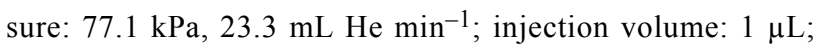
transfer line: $300{ }^{\circ} \mathrm{C}$; electron energy: $70 \mathrm{eV}$. The $\mathrm{GC}$ was programmed as follows: $5 \mathrm{~min}$ at $50{ }^{\circ} \mathrm{C}$, increasing at $5{ }^{\circ} \mathrm{C}$ $\mathrm{min}^{-1}$ to $320^{\circ} \mathrm{C}$, operating in splitless mode ( $60 \mathrm{~s}$ valve time). Conditions for the Agilent 7890A/Agilent 5975C system were as follows: Inlet pressure: $77.1 \mathrm{kPa}, \mathrm{He} 23.3 \mathrm{~mL} \mathrm{~min}{ }^{-1}$; injec- 
tion volume: $1 \mu \mathrm{L}$; transfer line: $300{ }^{\circ} \mathrm{C}$; electron energy: $70 \mathrm{eV}$. The $\mathrm{GC}$ was programmed as follows: $5 \mathrm{~min}$ at $50{ }^{\circ} \mathrm{C}$, increasing at $5{ }^{\circ} \mathrm{C} \mathrm{min}^{-1}$ to $320^{\circ} \mathrm{C}$, operated in splitless mode (60 s valve time); He carrier gas at $1 \mathrm{~mL} \mathrm{~min}^{-1}$ (HP-6890) or $1.2 \mathrm{~mL} \mathrm{~min}^{-1}$ (Agilent 7890A).

Retention indices $(I)$ were determined from a homologous series of $n$-alkanes (C8-C35) [19]. Identification of compounds was performed by comparison of mass spectra to the Wiley-6 Library, NIST 07, and the Essential Oils Library (Massfinder) and gas chromatographic retention indices, as well as by comparison with synthetic samples. Details can be found in the supporting information. The relative emission of volatiles was roughly estimated from peak areas, although overlapping peaks from the medium and the known difficulty in using CLSA for quantification allowed for only a rough approximation.

\section{Supporting Information}

\section{Supporting Information File 1}

Identification of compounds.

[http://www.beilstein-journals.org/bjoc/content/ supplementary/1860-5397-8-31-S1.pdf]

\section{Acknowledgements}

We thank the Fonds der Chemischen Industrie for financial support to S.S. Funding by the UBS Optimus Foundation (UBS) to S.H.E.K. and B.J.W. is gratefully acknowledged.

\section{References}

1. WHO, Global tuberculosis control - a short update to the 2009 report; WHO Press, 2009.

2. Cook, G. M.; Berney, M.; Gebhard, S.; Heinemann, M.; Cox, R. A.; Danilchanka, O.; Niederweis, M. Physiology of Mycobacteria. In Advances in Microbial Physiology; Poole, R. K., Ed.; Elsevier: Amsterdam, The Netherlands, 2009; Vol. 55, pp 81-318.

3. Sangari, F. J.; Bermudez, L. E. In Cytokines in Pulmonary DiseaseInfection and Inflammation; Nelson, S.; Martin, T. R., Eds.; Marcel Dekker, Inc.: New York, U. S. A., 2000; pp 213 ff.

4. Madigan, M. T.; Martinko, J. M.; Parker, J. Biology of Microorganisms; Prentice-Hall: New Jersey, 1997.

5. Wallis, R. S.; Doherty, T. M.; Onyebujoh, P.; Vahedi, M.; Laang, H.; Olesen, O.; Parida, S.; Zumla, A. Lancet Infect. Dis. 2009, 9, 162-172. doi:10.1016/S1473-3099(09)70042-8

6. Boehme, C. C.; Nabeta, P.; Hillemann, D.; Nicol, M. P.; Shenai, S.; Krapp, F.; Allen, J.; Tahirli, R.; Blakemore, R.; Rustomjee, R.; Milovic, A.; Jones, M.; O'Brien, S. M.; Persing, D. H.; Ruesch-Gerdes, S.; Gotuzzo, E.; Rodrigues, C.; Alland, D.; Perkins, M. D. N. Engl. J. Med. 2010, 363, 1005-1015. doi:10.1056/NEJMoa0907847

7. Knechel, N. A. Crit. Care Nurse 2009, 29, 34-43. doi:10.4037/ccn2009968
8. Phillips, M.; Cataneo, R. N.; Condos, R.; Ring Erickson, G. A.; Greenberg, J.; La Bombardi, V.; Munawar, M. I.; Tietje, O. Tuberculosis 2007, 87, 44-52. doi:10.1016/j.tube.2006.03.004

9. Syhre, M.; Chambers, S. T. Tuberculosis 2008, 88, 317-323. doi:10.1016/j.tube.2008.01.002

10. Pavlou, A. K.; Magan, N.; Jones, J. M.; Brown, J.; Klatser, P.; Turner, A. P. F. Biosens. Bioelectron. 2004, 20, 538-544. doi:10.1016/j.bios.2004.03.002

11. Syhre, M.; Manning, L.; Phuanukoonnon, S.; Harino, P.; Chambers, S. T. Tuberculosis 2009, 89, 263-266. doi:10.1016/j.tube.2009.04.003

12. Weetjens, B. J.; Mgode, G. F.; Machang'u, R. S.; Kazwala, R.; Mfinanga, G.; Lwilla, F.; Cox, C.; Jubitana, M.; Kanyagha, H.; Mtandu, R.; Kahwa, A.; Mwessongo, J.; Makingi, G.; Mfaume, S.; van Steenberge, J.; Beyene, N. W.; Billet, M.; Verhagen, R. Int. J. Tuberc. Lung Dis. 2009, 13, 737-743.

13. Mgode, G. F.; Weetjens, B. J.; Nawrath, T.; Cox, C.; Jubitana, M.; Machang'u, R. S.; Cohen-Bacrie, S.; Bedotto, M.; Drancourt, M.; Schulz, S.; Kaufmann, S. H. E. J. Clin. Microbiol. 2012, 50, 274-280. doi:10.1128/JCM.01199-11

14. Konno, K. Science 1956, 124, 985-986. doi:10.1126/science.124.3229.985

15. Boland, W.; Ney, P.; Jaenicke, L.; Gassmann, G. A. "closed-loop-stripping" technique as a versatile tool for metabolic studies of volatiles. In Analysis of volatiles; Schreier, P., Ed.; de Gruyter: Berlin, Germany, 1984; pp 371-380.

16. Dickschat, J. S.; Martens, T.; Brinkhoff, T.; Simon, M.; Schulz, S. Chem. Biodiversity 2005, 2, 837-865. doi:10.1002/cbdv.200590062 17. Bartelt, R. J. Anal. Chem. 1997, 69, 364-372. doi:10.1021/ac960820n 18. van den Dool, H.; Kratz, P. D. J. Chromatogr. 1963, 11, 463-471. doi:10.1016/S0021-9673(01)80947-X

19. Schulz, S.; Dickschat, J. S. Nat. Prod. Rep. 2007, 24, 814-842. doi:10.1039/b507392h

20. Mgode, G. F.; Weetjens, B. J.; Cox, C.; Jubitana, M.; Machang'u, R. S.; Lazar, D.; Weiner, J.; van Geertruyden, J.-P.; Kaufmann, S. H. E. Tuberculosis, in press. doi:10.1016/j.tube.2011.11.008

21. Prissick, F. H.; Masson, A. M. Can. Med. Assoc. J. 1956, 75, 798-803.

22. Zur Lage, S.; Goethe, R.; Darji, A.; Valentin-Weigand, P.; Weiss, S. Immunology 2003, 108, 62-69. doi:10.1046/j.1365-2567.2003.01564.x

23. Vindal, V.; Suma, K.; Ranjan, A. BMC Genomics 2007, 8, No. 289. doi:10.1186/1471-2164-8-289

24. Gupta, A.; Bhakta, S.; Kundu, S.; Gupta, M.; Srivastava, B. S.; Srivastava, R. J. Antimicrob. Chemother. 2009, 64, 774-781. doi:10.1093/jac/dkp279

25. Woo, P. C. Y.; Tsoi, H.-W.; Leung, K.-W.; Lum, P. N. L.; Leung, A. S. P.; Ma, C.-H.; Kam, K.-M.; Yuen, K.-Y. J. Clin. Microbiol. 2000, 38, 3515-3517.

26. Griffith, D. E.; Aksamit, T.; Brown-Elliott, B. A.; Catanzaro, A.; Daley, C.; Gordin, F.; Holland, S. M.; Horsburgh, R.; Huitt, G.; lademarco, M. F.; Iseman, M.; Olivier, K.; Ruoss, S.; von Reyn, C. F.; Wallace, R. J., Jr.; Winthrop, K.; on behalf of the ATSMycobacterial Diseases Subcommittee. Am. J. Respir. Crit. Care Med 2007, 175, 367-416. doi:10.1164/rccm.200604-571ST

27. Thorel, M.-F.; Krichevsky, M.; Vincent Lévy-Frébault, V. Int. J. Syst. Bacteriol. 1990, 40, 254-260. doi:10.1099/00207713-40-3-254 
28. O'Brien, M. E. R.; Saini, A.; Smith, I. E.; Webb, A.; Gregory, K.; Mendes, R.; Ryan, C.; Priest, K.; Bromelow, K. V.; Palmer, R. D.; Tuckwell, N.; Kennard, D. A.; Souberbielle, B. E. Br. J. Cancer 2000, 83, 853-857. doi:10.1054/bjoc.2000.1401

29. Blay, G.; Garcia, B.; Molina, E.; Pedro, J. R. Tetrahedron 2007, 63, 9621-9626. doi:10.1016/j.tet.2007.07.039

30. Atmosukarto, I.; Castillo, U.; Hess, W. M.; Sears, J.; Strobel, G. Plant Sci. 2005, 169, 854-861. doi:10.1016/j.plantsci.2005.06.002

31. James, B. W.; Williams, A.; Marsh, P. D. J. Appl. Microbiol. 2000, 88, 669-677. doi:10.1046/j.1365-2672.2000.01020.x

32. Sorlozano, A.; Soria, I.; Roman, J.; Huertas, P.; Soto, M. J.; Piedrola, G.; Gutierrez, J. J. Microbiol. Biotechnol. 2009, 19, 1259-1264.

33. Nawrath, T.; Gerth, K.; Müller, R.; Schulz, S. ChemBioChem 2010, 11, 1914-1919. doi:10.1002/cbic.201000296

34. Nawrath, T.; Gerth, K.; Müller, R.; Schulz, S. Chem. Biodiversity 2010, 7, 2228-2253. doi:10.1002/cbdv.201000190

35. Hayaloglu, A. A.; Cakmakci, S.; Brechany, E. Y.; Deegan, K. C.; McSweeney, P. L. H. J. Dairy Sci. 2007, 90, 1102-1121. doi:10.3168/jds.S0022-0302(07)71597-7

36. Callejón, R. M.; Tesfaye, W.; Torija, M. J.; Mas, A.; Troncoso, A. M.; Morales, M. L. Food Chem. 2009, 113, 1252-1259. doi:10.1016/j.foodchem.2008.08.027

\section{License and Terms}

This is an Open Access article under the terms of the Creative Commons Attribution License (http://creativecommons.org/licenses/by/2.0), which permits unrestricted use, distribution, and reproduction in any medium, provided the original work is properly cited.

The license is subject to the Beilstein Journal of Organic Chemistry terms and conditions:

(http://www.beilstein-journals.org/bjoc)

The definitive version of this article is the electronic one which can be found at: doi:10.3762/bjoc. 8.31 